paraplegia," and to which we will afterwards refer, which had many points in common with the early symptoms of the one just described.

In the present instance the first question which naturally suggested itself was-Were the symptoms real or assumed? At first all who saw the patient arrived at the latter conclusion, for the following reasons:-1. Although he complained of loss of power, it was quite evident from the powerfully contracting muscles that there was no true paraplegia. 2. The symptoms were such as could be assumed by anyone. 3. The patjent presented the appearance of a malingerer; in fact, so much so that our suspicions were aroused before any examination had been made. 4. All his sensations were normal, as also electrosensibility and contractility. It is true, when you stimulated one muscle the others were also thrown into contraction, but not more so than might be caused by the will in order to resist the electric effect. 5. According to his own confession, be had been dismissed from the American navy as a malingerer. In the last voyage he had been laid up, and well attended to for several months, and in the supposition of it being a feigned disease, it was aatural to suppose that he would continue it a little longer, especially as be had not been paid off. 6. There was no similar case recorded, nor any features at all resembling those mentioned in any work on medicine.

Our opinion gradually changed when the patient began to lose his appetite, suffer from intercurrent attacks of diarrhoo, and when his symptoms were found to remain unabated after all motives for malingering were removed, also when he was unobservedly watched, and found trying to move his legs, but all to no purpose.

Then the question arose, was it merely hysterical, or were the symptoms due to some organic changes in the nervecentres? The former question was answered in the negative, as he had none of the symptoms whieh we usually designate by that name, and, in fact, his non-emotional character and general bearing were the very reverse of hysterical. Besides, the symptoms were not those of hysterical paraplegia. In that affection there is paralysis more or less associated with numbness. Under the power of the will the muscles do not contract at all, or only feebly so; whereas, in this case, all the muscles contracted powerfully and the voluntary movement was only prevented by corresponding contraction of the antagonistic muscles, owing to an irradiation of the voluntary impulse. In hysterical paraplegia, as pointed out by Duchenne, the muscles have lost their electro-sensibility without losing their electrocontractility, whereas in this case both were intact. Sir Benjamin Brodie was of opinion that in hysterical paraplegia the power to will contraction was at fault, and not the power of ezecuting the orders of the will. In this case he could will contraction and contraction was executed, but not in the limited and purposive manner which be intended. The fact that electro-sensibility is lost in hysterical paraplegia would go to disprove Sir Benjamin Brodie's view that the power of executing the mandates of the will in that disease is not at fault; but be that as it may, in that affection the will calls forth no result, whereas in this case it induced a much more widely diffused effect than was intended, and the more intense the voluntary impulse, the more intensely and widely was its irradiation diffused. In walking, for instance, when about to take a step, if he found the foot more difficult to move than usual, he would make an increased effort to raise it from the ground, but with the result of more firmly fixing it thereto, and the more embarrassed he got, and the more he struggled, the more firmly did the foot remain, until at last he would perhaps direct his attention to the other foot, and then he could carry this one forward with comparative ease.

Having concluded that these anomalous symptoms were real, and due to some organic changes in the nerve centres, and as they were induced by a stimulus applied to the lower extremities as well as by voluntary impulse, we located the lesion in the spinal cord.

Dr. Stewart sums up his case as follows :- " The peculiar features of this case are, the almost perfect soundness of the sensory functions, and the undue excitability of the motor structures, whereby voluntary movement is prevented by corresponding and equivalent contraction of the antagonistic musiles, general contraction being also induced by peripheral irritation."
A careful perusal of these two cases will show that the only difference in the early symptoms was one of degree, not of kind; but this similarity in effect does not prove that the primary cause was the same in both cases. The peculiar motor excitability which was the prominent feature in both instances might be developed by different agents, such as by slight pressure on the antero-lateral columns, which I believe was the cause in our case, or by sclerosis, which Dr. Stewart thinks may have been the condition in his case. Dr. Stewart's case was still alive when his report was published, and although we have had the benefit of a postmortem examination, yet it would be quite impossible to say what was the precise condition of the cord during the early and most interesting stage of the case, owing to the progression of the vertebral disease and complete destruetion of the cord at the corresponding part.

During the pseudo-paraplegic stage of this case the symptoms were distinctly and solely referable to the anterolateral columns of the cord, and very probably due to slight pressure on these parts setting up irritation rather than destruction. As the disease of the vertebra extended and pressure increased, gradually complete destruction of these columns took place, thus causing true paralysis, and eventually the grey matter became involved, so causing abolition of reflex action. The fact of sensation remaining intact almost to the last shows that the posterior columns were late in being affected.

\section{A CASE OF CATALEPSY.}

BY WILLIAM O'NEILL, M.D., M.R.C.P. LOND.,

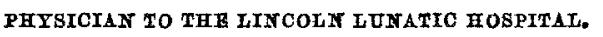

I HAVE had lately under treatment an interesting case of that obscure and extraordinary disease-catalepsy, and, as it is an affection not of ten seen in practice, it may be worth recording.

On Jan. 20th Miss G-, the subject of the disease, became a patient of mine. She is a fair-complexioned country girl of eighteen years of age, approaching embonpoint, and with considerable flaccidity of muscle. Her parents and six brothers and sisters are living and healthy, and the family history is free from the taint of insanity and epilepsy. But the patient has never been a strong girl, for she has always suffered from palpitation of the heart and difficulty of breathing, especially on exertion. The origin of those symptoms, however, her mother could not connect with any definite disease. The girl suffered occasionally from tic and other neuralgic affections, and seldom rose in the morning free from headache. She also complained of a defective appetite, of pain in the stomach after eating, and of constipation of the bowels. The catamenia were rather profuse, came on every three weeks, and continued for a week. The pulse was 84 , weak and visible, and the respiration 24. She conld not assume the horizontal position in consequence of the choking sensation and shortness of breathing which it caused; consequently, she had to sleep with her head pillowed high. The lungs were healthy, but in the precordial region there was slightly increased area of dulness, and over the same region a loud double bellows murmur could be heard, loudest at the apex of the heart, but still very loud at the base. This murmur was conveyed along the arteries in the neck, and could be heard with great distinctness all over the front of the chest, and it could also be heard over the back of the chest, especially over the left side of the back.

But the patient and her mother were not so anxious about the chest affection as they were about fits, which attacked the girl twelve months ago, in consequence, they believed, of her having been subjected to frights. In tho evening of Jan. $20 \mathrm{th}$, about six o'clock, I saw her for the first time in one of these fits, about half an hour after it had begun. I found her where she had been placed at the outset of the seizure, sitting on a couch with her back apparently resting against a few pillows. She seemed as if she were in a deep sleep, her eyes closed, and her head inclined a little to the right side. The face was flushed, 
the neck slightly swollen, especially on the right side, and the skin was hot and perspiring. I now made an attempt to examine a pupil, but the eyelid spasmodically resisted, so that I had a little difficulty in ascertaining that the pupil was sensible to light. I pushed her gently from the position in which she was sitting, and without making any effort to recover ber equilibrium, she slid down like an inanimate body, and would have fallen if she had not been prevented. I wished to make her drink some fluid, but her teeth were so firmly clenched that $I$ found it nearly impossible to do so. I pinched her arm, but the countenance gave no indication of pain, clearly showing in this instance that she was not sensitive to external stimuli. I raised an arm; the muscles of it showed a considerable amount of rigidity, fur when $I$ let it go, it fell slowly in a peculiar interrupted way, making two halts or pauses before the hand fell on the knee. The muscles of the legs were in a similar condition to those of the arms, but the muscles of the neck, back, and thighs were so hard and rigid that they retained the girl firmly fixed in any position in which I ch ise to place her. I had, moreover, to use great caution not to put her in any posture which would embarrass the breathing. From experience, her relatives had found that the breathing was easiest whilst sitting, consequently it was in this position she passed through the fits. Her pulse was at the time 130, and very weak, the respiration 40 , and temperature 100 . Whilst watching the patient I heard her faintly sob twice or thrice, and as time passed on, the face and skin, which were at the onset flushed and hot, gradually became pale and cold, so that in about an hour and a balf after the fit had begun, although in a very hot room, the surface of her body became cold, the feet, arms, and hands very cold, while the palms of the hands were wet with perspiration. Towards the end of the fit the pulse had fallen to 100 , but the respiration remained at 40 ; the surface became perceptibly warmer, temperature about $96^{\circ}$.

I saw her come out of the seizure. She sighed a few times, moved the head slightly, some water ran from the eyes and nose; after a few minutes she opened her eyes, but could not speak ; in half an hour she could speak in a whi-per, but it was two hours before she had recovered sufficiently to walk upstairs to bed; the night's rest, however, was required to restore her to her usual state.

When explaining her sensations immediately before an attack she said she felt sudden palpitation, dizziness, and general numbness. She also said that sometimes she was aware of what was passing about her during the fit, and could bear words when distinctly spoken, and at other times she neither knew nor heard anything that was occurring. I may add that each fit came on every evening within a few minutes of half-past fire o'clock, and continued two hours and a half, and that one evening in the week or ten days she escaped having a fit.

Jin. 24,h.-I saw Miss G- again in a fit this evening. The symptoms of it were similar to those before mentioned, excepting that the skin at the beginning was not so hot, the respiration so rapid, nor the pulse so quick, as on the former occasion. Towards the end of the fit the extremities became excessively cold. It seized her this evening somewhat later than usual when she was at tea. Her general health is a little better than it was on the 20 th

27 th. - The patient continues to improve. The breatbing is better, she can walk farther, and can sleep with her head lower than before. The fit this evening came on about six o'clock, being nearly half an hour later than usual. Sho did her utmost to keep it off, but it attacked her as she was throwing a ball at her uncle, and when bops and girls were laughing and talking in the room.

Feb. 7 th.-Last night the girl had a fit, but on the three preceding evenings she had none. So long an interval from them has not occurred for the last six months. The patient looks thinner and paler, and has lost the flabby appearance she has had. She can now take a good deal of walking exercise, and can sleep with her head a pillow or two lower than before.

25 h. - The patient has had only one fit during the last fortnight, but each evening about seven o'clock she becomes, to use her aunt's expression, "as cold as ice." The temperature falls to $96^{\circ}$, or even lower. The cold stage of the fit, then, still remains, although the other symptoms of it have disappeared.

March 15th. - Mise G- has lost her fits and all traces of them, and is in as good bealth as it is possible for a person suffering from valvular disease of the beart to be in. This case was to me a most interesting one, inasmuch as it was the first example of idiopathic cutalepsy I had seen. I have witnessed on a few occasions cataleptic symptoms complicate insanity, epilepsy, and, I believe, brain disease. A few months ago I had a patient who suffered from aggravated hyiteria, whose fits were composed of a curious mix ture of hysteria and catalepsy. In those cases the symptoms were more or less transient and limited, and bore only a partial resemblance to the case which I bave related; they were symptomatic symptoms, whereas the case of this girl was an idiopathic affection.

The conditions of the fit in Miss G- were very well marked : the sudden seizure without convulsions, the more or less abolition of sensation and voluntary motion, and the trnic rigidity of the muscles. Stnsatic $n$ was not, in all the fits which $I$ witnessed, quite in abeyance, for in some of them she was cognisant of what was passing about her and in all probability this partial abolition or sensibility is the mental state in the majority of patients suffering from catalepsy pure and simple. The stiffeving or rigidity of the muscles was, in several of the fits in which I saw her sufficiently intense to exemplify in a remarkable way the character of the muscular system in catalepsy. The symptoms representing the genal state, ranging from febrile beat to icy coldness, the coldness continuing for about a fortnight after the ordinary attacks had ceased, must be very unusual. They were the symptoms which gave the relatives the most anxiety, and impressed onlookers with the strangeness and gravity of the case. During the cold stage the heart's action became so weak that the pulse could hardly be felt; the respiration during the same time was generally shallow and noiseless.

The causes of catalepsy are difficult to divine. The disease does not, it appears, attack the strong and robust, but the weak and delicate, who bave highly sensitive and excitable nervous temperaments. These people, so long as their various bodily functions are performed in a healthy manner, enjoy, for them, good health; but when, from disease or any other exhausting cause, th t healtby balance is lost, and they are at the same time exposed to some prolonged mental emotion, they lose their power of self-control and catalepsy may be the result, which, as regards patho$\log y$, is the most obscure of its kindred nervous affections, the best understood of which is mainly seen as "through a glass darkly."

In the case of this patient the depressed vitality into which she had fallen may have acted as the predisposing canse, the frights may have acted as the exciting canse, and the nervons idiosyncrasy which doubtless is in some way implanted in the girl determined the disease, and the outcome was catalepsy. The fit having once occurred, the tendency to repeat itself was strengthened by each repetition, manifesting that mysterious habit of the body which few can satisfactorily explain. It is noteworthy the length of time the disease has lasted, and also the great regularity and even punotuality of the attacks, as if the nervous system generated nerve-force to be exploded each day at a given time.

The treatment of the case was very satisfactory. After having attended to the state of the patient's digestive system, I prescribed for her a mixture composed for the most part of bromide of potassium and fluid extract of ergot, and of this mixture she took at first a dose every three or four hours, and afterwards a dose three times a day, and under this treatment she began immediately to improve. The headache, flushings, and the febrile stage of the fits began to subside, so that at the end of a fortnight few traces of those symptoms remained. By this time she also looked thinner and healthier, could take a considerable amount of exercise, and was able to sleep with her head lower. In fact her general health was improved in all respects, with the exception of the fits, and they remained, although not so severe as before. I now ordered in addition to the mixture, a pill of oxide of zinc and extract of hyoscyamus to be taken three times a day. The zinc seemed to have acted quickly on the fits, for they began very soon to disappear. Latterly I substituted for the oxide the valerianate of zinc and the extract of cannabis indica, and since beginning this change sbe has not had a single fit. The bromide of potassium and fluid extract of 
ergot acted admirably in improving the general state of the patient, but had no effect in strpping the fits; this was reserved for the oxide of zinc, and more especially for the valerianate of zinc.

\section{A CASE OF INVERSION OF THE UTERUS, OF SIXTEEN MONTHS' DURATION, SUCCESSFULLY TREATED BY OPERATION. ${ }^{1}$}

By WILLIAM A. WILSON, M.D.

IN September, 1875, I was consulted by Mrs. M- aged twenty-one, who had been confined of her first child on the 21st of December of the previous year. She stated that her labour was natural and the child quickly born, but the placenta was adherent, and some difficulty was expe. cienced in its removal, and she suffered for three days from what she described as after-pains. About three weeks after her confinement, while at stool, something came down beyond the vulva, which a neighbour said was the womb, and pushed it back into the vagina. She has complained ever since of pain of a dragging character, and a sense of great discomfort, and every few days she has had a slight bloody discharge from the vagina. About three months ago she became troubled with frequent desire to micturate, with great pain in the back. She was somewhat anæmic, was nursing her child, but felt unable to undertake her usual household duties.

On examination per vaginam, I found a tumour about the size of a hen's egg, pear-shaped, firm to touch, not painful, attached to the inner surface of the anterior lip of the uterus by a pedicle about the thickness of one's thumb; the finger could be passed between the pedicle of the tumour and the posterior os. I diagn'sed a fibroid polypus of the uterus, and advised its removal, recommending her to wean the child.

I was requested to see her again on Dec. 1st, as she had had severe flooding on several occasions since I last saw her; she was now weaker, and much more anæmic. I urged her to have the tumour removed, and she now gave her consent.

Accordingly, on Dec. 3rd, I seized the tumour with a vulsellum, drew it beyond the vulva, and passed the wire loop of an écraseur over the tumour to its pedicle. On passing my finger up to guide the wire previous to tightening it, I found the surface of the tumour terminated above in a perfect cul-de-sac, its surface being continuous with that of the vagina; the dragging down of the tumour had quite obliterated the posterior lip of the os ateri. It was now evident that I had to deal with a case of inversion of the uterus, and this explained what had struck me whenever the tumour was exposed to view-viz., its great vascularity. The patient was immediately put to bed, and a morphia suppository was intr duced into the rectum. No bad effects followed, and three days later I made an ex. amination in the following manner. I passed a sound into the bladder, and introduced a finger into the rectum, and found, from the absence of the body of the uterus between the sound and the finger, that my diagnosis of inversion was confirmed.

I proceeded now to attempt reduction by forcible taxis by placing the left hand over the hypogastric region, and introducing the right into the vagina, and, grasping the uterus, attempted to reduce it. This I did for about $t$ wenty kninutes daily for fourteen days. At the end of this time very little progress had been made. I could only sink the uterus about half an inch within the external os. I had now to desist for a time, as the bæmorrhage had returned. Tincture of perchloride of iron and other astringents were applied locally till the bæmorrhage ceased, when $I$ again made repeated attempts at reduction under chloroform, with no better results. I then tried keeping up elastic pressure with an air pessary, and occasionally attempting reduction under chloroform. The pessary was kept in the vagina for a fortnight with no benefir.

\footnotetext{
1 Read before the Greenock Medical Society.
}

In April it was evident that unless some means were adopted capable of arresting the hæmorrbage which was exhausting her she would soon succumb. She was now quite anæmic, extremely weak, breathless, had slight œdema of the feet, her appetite had failed, and her stomach would scarcely retain even the simplest food.

I now determined to put in practice an operation first successfully performed by Dr. Barnes, of London.2 some years ago. On the 14th A pril, 1876, assisted by Dr. Marshall I placed the patient on a table, on her elbows and knees, drew down the uterus beyond the vulva, introduced a Marion Sims' speculum into the vagina, and with a curved bistoury made three longitudinal incisions into the constricted neck of the tumour, each incision about threequarters of an inch in length, and nearly a quarter of an inch in depth; I then passed the uterus back into the vagina, and proceeded to re-invert. The reduction was effected easily, and with a distinct feeling of tearing of the uterine tissue. There was very little bæmorrhage during the operation. The patient was placed in bed, aud an opiate administered. She felt sick, and vomited during the afternoon, but passed a good night. She did well for a fortnight after the operation, had no pain, sickness, nor fever, was taking her food and gaining strength, when she was seized with a severe attack of enteritis, caused, as she herself supposed, by partaking too freely of rich food. This reduced her very much, and it was not till the end of June that she was quite well, and able to resume her usual duties. Four months after the operation menstruation took place, and she has been regular ever since. I made an examination in September, and found the uterus in situ, two inches in length, but not so movable as usual, there being some adbesion of the body of the uterus behind. She had improved in strength, and expressed herself as being as strong as she had ever been.

Remarks - As regards the diagnosis of inversion of the uterus from polypus, there is no difficulty about it; it is only on account of the rarity of inversion that its existence is liable to be overlooked, and the means of distinguishing the two diseases apt to be neglected.

The stricture appeared to be at the inner os. The uterus could easily be pushed into the external os, and when in that position the finger could be readily passed between it and that part of the uterus lying within it. When reinverting after the incisions had been made, a distinct sensation of laceration of the uterine tissue could be felt. Dr. Mattbews Duncan, in an article on this subject in the Edinburgh Medical Journal, ${ }^{3}$ gives it as his opinion that it is on account of these lacerations of the body of the uterus that replacement of the inverted organ is obtained; and that the incisions should be made into the body of the uterus, as " complete inversion of the uterus is a condition of the body of the uterus, and that the condition of the cervix is of trivial import."

The removal of an inverted uterus is not justifiable until all means of reduction bave been tried, and among these measures we must class the operation of incising the constricted internal os, or part of the uterus itself, and afterwards attempting reduction, either by forcible taxis or by more gentle measures, as by means of air-bags in the vagina.

3 "Medico-Chirurgical Transactions, vol, lii., p. 179.

3 March, 1877 : " Five Cases of complete Inversion of the Uterus."

Dublin Sanitary Association.-The necessity for the existence of a sanitary association in Dublin was never more apparent than at present. That such an association exists and does good work implies that the sanitary authorities do not perform their duties efficiently. 'The annual meeting of the Association took place last week, being presided over by the President of the College of Physicians, Dr. Samuel Gordon. The report for the preceding year alluded to the work done by the committee in reporting nuisances, in suggestions about the late threatened epidemic of small-pox, and recommendations about burning infected clothing, \&c.; the com mittee, in conclusion, expressing their conviction that the Association has done and is doing a most useful work, and that the fruits of its labours are already apparent in the increased interest taken by the public in health questions and in the improvement in the sanitary administration of the city since the formation of the Association. 